\title{
Paying donors and the ethics of blood supply
}

\author{
Pablo Rodriguez del Pozo University Carlos III de Madrid and Health Care Consultant, Government of \\ Argentina
}

\section{Author's abstract \\ Countries may be erring in the current trend towards relying entirely on volunteers to fulfil blood and plasma needs. Complementing uncompensated blood with compensated blood is vitally necessary not only effectively to meet the blood and plasma needs of most countries, but it is also ethically sound.}

\section{Introduction}

Throughout history the most sacred, the most fantastic, the most prosaic properties have been attributed to blood. Today medical and technical advances have made blood a therapeutic resource of extraordinary importance and, thus far, an irreplaceable one. A safe, ample blood supply is a cornerstone of any health care system, and the lifeline of that supply is its donors.

Donors can be divided into two broad categories: paid and unpaid, the latter most commonly referred to as voluntary. In this article I will point out the drawbacks of paying donors which have prompted many nations to adopt all-volunteer systems. But an all-volunteer model is not exempt from defects and I shall attempt to explain some of these defects and explore the question of when resorting to paid donors may be acceptable. I leave open the possibility of making certain exceptions to the principle of an all-volunteer system on the basis that so-called practical problems of blood-supply models, such as the shortage of blood and plasma, are loaded with compelling moral considerations.

In weighing the ethical problems surrounding paid donors, it is important to consider not simply the payment per se but also the blood-supply system as a whole. In the following pages I will try to highlight the most central issues that need to be borne in mind when shaping blood-supply strategies.

\section{Cash blood: drawbacks}

Blood-supply policies have long been assessed from the viewpoint that the appropriate model is that which contributes to the greatest good for the greatest number. Naturally, the consequences of any given act are a factor to weigh, and when an action or pattern of conduct is considered ethically neutral in abstracto, the consequences will be the measure of its ethicality. Kantian scholars may find this utilitarian criterion objectionable, but it currently constitutes the primary guide to moral conviction at the policymaking level.

In fact, so-called cash blood has seldom come under fire on ethical grounds when the exchange is performed under fair and equitable conditions. Criticism of remunerating donors for blood has, rather, centred primarily on the negative consequences this transaction may produce. Richard $M$ Titmuss, the leading critic of paid blood suppliers, identified the following three main negative consequences in his landmark 1971 book, The Gift Relationship (1).

First, Titmuss contended, commercial suppliers discourage altruistic, voluntary donations, provoking shortages and driving up costs in the blood-supply system (2). Titmuss provided almost no evidence to prove this assertion and critics soon pointed this out (3). Still, it seems likely that when suppliers are paid, potential non-cash donors lose the sense that their contribution is absolutely necessary. Erroneously or not, they probably believe that blood-needs will be fulfilled through alternative means. Furthermore, voluntary donors may well feel their blood is transformed into a commercial good, and giving it away freely seems somehow unfair. As a 1989 study in Spain showed, in order to give, voluntary donors require the certainty that their blood will not become merchandise (4).

Secondly, Titmuss said, the blood of paid donors necessarily transmits more transfusion-related diseases than that of voluntary donors (5). He wrote primarily with hepatitis in mind, but the AIDS epidemic has given his assertion even greater relevance now, when all blood ought to be considered potentially HIV-carrying until proven otherwise. Yet Titmuss failed to provide convincing support for his point. As Harvey M Sapolsky notes, during the 1960s Japan switched from a paid to an all-volunteer system without a change in the incidence of hepatitis. And major institutions such as the Mayo Clinic and the Massachusetts General Hospital have paid donors with a low rate of post- 
transfusion hepatitis (6). Titmuss apparently overlooked a vitally important possibility: the high blood-quality he saw in Britain may have been due not to the nation's all-volunteer system but rather to the very rigorous screening process required of donors.

Thirdly, Titmuss argued, paid-donor systems exploit the weakest socio-economic groups because commercial blood collectors stand to make higher profits dealing with needy or ill-informed people (7). This is perhaps Titmuss's most compelling argument from an ethical standpoint, since the human rights of the individual are at stake.

But it is important to clarify a point here. The fact that payment induces an individual to give blood does not automatically mean that the donor lacks autonomy, is poorly informed, or is jeopardizing his or her dignity, right to health, or physical integrity. If I am offered $\$ 10,000$ for a half-litre of blood, I may freely choose to donate and we can all probably agree that I have not been exploited. The ethical conflict arises only when lower socio-economic groups, out of urgent financial need, give blood in exchange for low sums of money, or when they unknowingly or even knowingly jeopardize their health. These groups are exploited if, under different financial circumstances or with full information, they would have refused to donate.

Titmuss was evidently referring to the exploitation of the destitute in the developed world, especially the United States. But the way commercial collection stations may exploit the poor of the developing world deserves special attention. Piet Hagen, in his book, Blood: Gift or Merchandise, documents the myriad of abuses in the bloodmarket in developing countries. In a Managua plasma centre, for example, under the Somoza dictatorship, doctors extracted for export unlimited amounts of plasma from poor, undernourished Nicaraguans for meagre sums of money and without regard for their health (8). Such exploitation certainly is to be avoided, although let us keep in mind that unlike organs, blood is a replenished resource, the taking of which need not cause irreparable harm.

\section{All-volunteer system: limitations}

Titmuss's attack on cash blood proved convincing, and during the 1970s many nations moved to switch to a system reliant on non-cash donors. Spain, which had a long tradition of paid suppliers, in 1975 took the first steps towards an all-volunteer system, definitively switching over ten years later. This allvolunteer model currently prevails in Western Europe, but it is not without its own shortcomings.

The all-volunteer system I will explore is that in which the blood supply is considered a community, rather than an individual, responsibility and one in which blood is always held as a 'special gift', not to be exchanged for money or any other good (9).

I will concentrate on three of the shortcomings of? the all-volunteer system: (1) the risk that banning payment gives rise to an illegal blood market; (b)o the unjustified, uncompensated, net transfer oforesources from one sector of society to another, and $\overline{\bar{c}}$ (c) the shortage of blood derivatives. Often I will $\widehat{\Phi}$ make reference to Spain in examining these threen points, in the interest of offering a 'middle-of-the- road' European country which has a relatively young. democracy and which is neither underdeveloped nor $\vec{\omega}$ fully developed.

\section{The risk of an illegal market}

The legal prohibition of cash blood does not stop the play of economic forces, nor does it prevent people from thinking of blood in monetary terms음 (10). It continues to be necessary to supply blood, and blood is often in desperate demand; coronary bypass surgery, for example, requires 12 to $20^{\frac{\omega}{\alpha}}$ donors. This is fertile ground for the growth of an illegal blood market, both at the domestic and $\vec{g}$ international level. Historically, such markets have? surfaced (11).

Moreover, illicit blood circuits offer the mosts dubious guarantees of quality, conservation, and respect for the rights of donors. Now, with the advent of AIDS, clandestine blood suppliers would这 be certain to cause a health catastrophe which any public-health policy must prevent.

\section{The transfer of resources: who pays for voluntary blood?}

When remuneration is ruled out, potential donorsoare frequently offered non-monetary benefits in? exchange for blood. But non-cash benefits are noto automatically bereft of economic value; someone covers the costs of the blood donated, albeito indirectly.

For example, Spanish law specifies that 'time spent donating blood is for all purposes considered to be fulfilling a public and personal duty' (12) This means that workers can leave their jobs to give blood and that management must absorb the cost either of lower productivity or of temporarilye replacing employees. That is to say, the employero effectively transfers resources, easily expressible in monetary terms, to the blood-supply system? Assuming that an all-volunteer system requires at? least 50 donors per 1,000 people to give whole blood twice annually (and plasma much more尺 frequently), the transfer of resources become $\stackrel{\mathbb{\Omega}}{\mathbb{Q}}$ considerable. A programme to compensateo employers for employees' lost time seems an unsatisfactory solution on two counts. First, ito would solve neither lower production levels nor reduced productivity, particularly in small, extremelys specialized firms which depend on highly traineof 
personnel. Second, as with most programmes based on criteria other than productivity and merit, such a programme would open the door to abuse and fraud (13). In sum, from an ethical standpoint, it is difficult to justify why one sector should bear the financial burden of the blood-supply system, which is ostensibly the responsibility of the entire community. If the blood supply is to be a shared responsibility, it must be shared fairly.

\section{The shortage of plasma}

The all-volunteer model can, by and large, satisfy the need for whole blood, although not without periodic shortages (14). But not all patients require whole blood. Some need red cells, others platelets, and others plasma or plasma fraction. Giving each patient only the fraction required dramatically improves the total component supply and is desirable from a medical standpoint (15). The plasmapheresis procedure allows donors safely to give plasma alone more frequently and without wasting cells (17).

But statistics show that only 20 per cent of plasma collected in all-volunteer-supply nations comes through plasmapheresis, because the vast majority of donations are of whole blood from which plasma is later separated (18). Moreover, the amount of plasma so obtained is frequently not enough to meet the medical requirements of the population (18). A 1986 Spanish government report emphatically concluded: 'It can be affirmed that the production of plasma [in Spain] is insignificant compared to need ... this is principally because ... the donation of plasma is hardly practised and separating from whole blood is totally inefficient' (19).

Why do donors prefer to give whole blood? Simply because plasmapheresis is much more demanding in terms of time. Up to two hours may be necessary to extract the appropriate amount of blood, separate the plasma, and return the cells to the donor's bloodstream (20). Potential donors specifically cite time as the factor which inhibits them from giving plasma (21), and thus at present an all-volunteer system almost inevitably will suffer from a chronic dearth of plasma. As with any other market imbalance, the way to narrow the gap between supply and demand is either to reduce demand or increase supply. Since decreasing demand is currently unfeasible, strategies should centre on overcoming the reluctance to donate plasma by offering specific incentives or by reducing discomfort.

Nations where all blood donations are voluntary often resolve plasma shortages by importing from abroad. Spain, for example, imports three out of every four litres of plasma processed (22), at an estimated cost of $\$ 20$ million annually (23). Not only is this substantially more expensive than domestic plasma (24), but large-scale importing also involves a transfer of health-care resources abroad. For Spain at least, the demand for plasma could be fulfilled domestically at less expense, and the savings could be allocated to other health-care needs of equal urgency.

Even more important, there is no ethical difference between buying from countries where plasma supplies come from paid donors (25) and buying from domestic donors one-by-one. The moral misgivings surrounding paid donors, particularly the possible exploitation of the destitute, are transferred across national borders but by no means resolved. Importing also fails to eradicate health dangers associated with cash blood, and it introduces new risks, since standards are even harder to maintain on the plasma pools (26).

\section{Paying donors: conditions and requirements}

The all-volunteer system is, then, imperfect and a model which admits some paid donors seems reasonable, even though a number of questions persist. Rather than pit cash against non-cash donations, we should probably use both resources concurrently.

We should maintain and expand the numbers of voluntary donors. Here it is essential to assure would-be donors that, despite the existence of cash blood, their own blood is vital and will not end up as a market good. This can be done through public information campaigns aimed at making citizens aware of the usefulness of donating blood and plasma, and the value of community solidarity. Potential donors must also be informed that what blood facilities charge for their products is for the added value rather than the blood itself.

We must also avoid the drawbacks of paid blood. To achieve this we should ensure that sanitary conditions prevail and that paid donors are not exploited. Titmuss's reservations are valid, but they are by no means insurmountable.

\section{Sanitary conditions}

By asserting that paid blood necessarily carried more disease than volunteer blood, Titmuss seemed to assume that any donor was acceptable to blood collection agencies. But the foundation of any blood supply system must be a very thorough screening process, so that only qualified donors give their blood.

An all-volunteer system itself is no guarantee against transmission of disease through blood transfusions. Arthur Caplan points out, for example, that the rates of hepatitis from transfused blood in Japan, which has a voluntary system, have been high, while those in Sweden, where a market system prevails, have been low (27). By asserting that paid blood necessarily carried more disease than volunteer blood, Titmuss seemed to assume that any individual was welcome as a paid supplier. But the 
foundation of any blood-supply system must be a very thorough screening process, so that only qualified donors give their blood. Measures oriented towards selecting and maintaining registries of donors can include a careful and confidential clinical history, drug and alcohol testing, and tests for, among other transmissible diseases, hepatitis and AIDS (28).

Improved screening ought to be accompanied by better economic incentives in order to attract lowerrisk groups, such as the middle-aged, young women, and the gainfully employed. Cash blood is not necessarily bad blood; cheap blood probably is. As Kessel noted, the problem is not that people receive cash for donating, it is that healthy people are not paid enough to meet the needs of the blood-supply system (29). At the same time, the donor should not receive any compensation until the blood has been judged acceptable, a measure which could help discourage high-risk individuals from giving. Further to promote safety, we can hold blood banks liable for quality control and require them to pay a fixed amount for possible damages, as some have proposed (30). Finally, government supervision of blood collection can help to ensure sanitary conditions prevail.

The fear may persist that paid donors will withhold medical information. But today strict testing, together with medical and social follow-ups, should discourage domestic donors at least from withholding potentially dangerous information, and under certain circumstances authorities could take steps to prosecute those who conceal such data.

\section{The exploitation of the underprivileged}

Cash blood has been widely held to exploit the poor, and in the case of the developing world this tendency is particularly prevalent. But the root of exploitation is not cash per se; rather, it is the lack of controls over blood-collecting facilities.

Furthermore, abuses in developing countries normally grow out of a ban on cash blood in the developed world. Prohibiting payment of donors produces chronic plasma shortages that force allvolunteer countries, many of which are in the developed world, to import. The needed plasma often comes, either directly or indirectly, from the developing world, where blood is obtained from truly desperate suppliers (31).

If, on the contrary, cash blood were to be generally accepted, the need to import plasma would diminish. Blood services could be required to ensure that domestic donors were not risking their health and that they had the capacity to give informed consent. Again, government oversight could play an effective role. The greater economic incentives proposed above would also help eliminate the possibility of exploitation of the needy.

Exploitation is a particular risk in habitual or so-called professional donors who, as Hagen says, 'may become so dependent on their sales of blood or plasma that they are tempted to endanger their own? health' (32). A simple way to minimize this risk is to $\overrightarrow{=}$ set a fixed legal limit on the quantity and frequency? of donations, and on subjective criteria such as blood? composition, within an ample safety margin.

\section{Conclusion}

In the absence of corrective measurements, paymen 5 of donors has drawbacks. Nonetheless, the completebanning of cash blood seems unwise and finallycu ineffective. An all-volunteer system likewise has its? faults, including the risk of illegal markets, the unfair sharing of the financial burden, and the shortage off blood derivatives. A nation committed to this model would require a strong political will to prevent illicitiw markets from developing, creative policy-making too spread the financial burden, and a technological breakthrough to simplify plasma collection in order ${ }_{3}$ to avoid blood derivative shortages.

Acceptance of some cash blood therefore seems to? constitute sound, sensible policy. But accepting paid $\vec{c}$ blood should be accompanied by the institution of measures such as (a) a public education campaign to promote voluntary blood donations for mosto purposes; (b) a thorough screening process to detect transfusion-related diseases in would-be donors; (c) greater financial incentives to draw more and lower- $\frac{0}{8}$ risk donors; (d) tight medical controls to ensure that the health of donors is not prejudiced, and (e) $\overrightarrow{\overrightarrow{0}}$ effective government monitoring of the blood collection process to ensure safe, non-exploitative conditions.

Contamination poses a threat to all systems of blood collection, and there are no conclusive ${ }^{\infty}$ scientific studies from recent years to demonstrate 3 . that blood from paid donors runs a higher risk of contamination than that from uncompensated? donors. Thus, it cannot be argued that blood and plasma from volunteers is necessarily safer from? infection. But proponents often advocate an all $\frac{D}{0}$ volunteer system on moral grounds. Returning to the criterion of broad effectiveness mentioned at the start of this paper, a 'mixed' system may bơ considered morally acceptable. Relying entirely on volunteer donors at present means tolerating shortages of blood and plasma. This, in turn, means depriving individuals who need blood now, as well as retarding research and development projects which? rely heavily on paid blood. Even in the unlikely situation that all infections from an all-voluntees system could somehow be remedied, these shortages would persist. And moral decisions that affect individuals should be evaluated not simply in the abstract but also by taking into account the finat consequences.

Thus, the most economically rational ans socially constructive model seems to be a system in̄. which volunteerism is the rule and payment the 
exception. Donations foster social ties and a general sense of community solidarity, which may well constitute one of the highest values in modern democracies (33). But each society must, within its historical context, opt for the least discordant model, one which most nearly harmonizes different interests, respects human rights, allows for longer term planning of health-care policies and investment, and finally meets the medical needs which only blood and blood derivatives can fulfil.

Pablo Rodriguez del Pozo, MD, $\mathcal{F D}, \mathrm{PhD}$, is a health care consultant to the government of Argentina.

\section{References and notes}

(1) Titmuss R M. The gift relationship: from human blood to social policy. London: Allen \& Unwin, 1971.

(2) See reference (1): 237-246.

(3) Arrow K J. Gifts and exchanges. Philosophy and public affairs 1972; 1, 4: 343-362.

(4) España, Ministerio de Sanidad y Consumo. Estudio de actitudes de la población ante la docación altruista de sangre [Spain, Ministry of Health and Product Control. A study of the attitudes of the population towards altruistic blood donation]. Madrid: 1989: 83.

(5) See reference (1): 142-157.

(6) Sapolsky H M. Aids, blood banking and the bonds of community. Daedalus 1989; Summer: 145-163.

(7) See reference (1): 90-119. On the likelihood of the poor to become paid donors, see Hagen P J. Blood: gift or merchandise; towards an international blood policy. New York: Alan R Liss, 1982: 35 (with broad references).

(8) See reference (7): Hagen P J: $163 \mathrm{ff}$.

(9) I borrow the definitions from Drake A W, Finkelstein S N, and Sapolsky H M. The American blood supply, Cambridge, MA: MIT Press, Series in Health and Public Policy, 1982; 5: 14; and US Food and Drug Administration. Current good manufacturing practices, blood and blood products. Washington, DC: 1978: 2147.

(10) Thorne E D. Tissue transplants: the dilemma of the body's growing value. The public interest 1990; 98: 37-48.

(11) Commercialization in transplantation: the problems and some guidelines in practice [editorial]. Lancet 1985 Sept 28: 715-716; see also: Sales of kidneys increasing as transplants proliferate [editorial]. American medical news 1985 Nov 15: 18.

(12) Article 6 of Royal Decree no 1945/85 issued on Oct 10,1985

(13) For example, the cost-conscious management of a building company would automatically declare rainy days 'donation days'.

(14) España, Ministerio de Sanidad y Consumo. Plan nacional de hemoterapia [Spain, Ministry of Health and Product Control. National blood therapy plan]. Madrid: 1990: 82 .
(15) Wallace E L. The case for a national blood policy. In: Eckert R D, Wallace E L. Securing a safer blood supply: two views. Washington, DC: American Enterprise Institute for Public Policy Research, 1985: 85-153.

(16) In Spain, specifically, that figure is less than 20 per cent. See reference (14): 32.

(17) See reference (9): Drake et al: 8.

(18) See reference (7): Hagen P J: 191.

(19) España, Ministerio de Sanidad y Consumo. Un análisis estructural del sistema hemoterápico en Espana. [Spain, Ministry of Health and Product Control. $A$ structural analysis of the Spanish blood therapy system]. Madrid: 1986: 27.

(20) See reference (9): Drake et al: 9.

(21) See reference (4): 77 .

(22) See reference (14): 43.

(23) See reference (19): 38.

(24) See reference (19): 39.

(25) Of Spain's plasma imports, $94 \cdot 2$ per cent come from the United States, where plasma donors are mainly paid. See reference (19): 61 .

(26) Steinfelds P. Blood money: should a rich nation buy plasma from the poor? No. The Hastings Center report 1972; 12, 6: 9-10. A heat treatment that kills the HIV virus in the processing of plasma is now available. This considerably reduces the risks of infection in recipients of plasma derivatives, such as haemophiliacs. Nonetheless, the method is not 100 per cent safe, and some risks still remain. See reference (6): 174. There are several studies on the remaining risks, including: Chitwood D D et al. The donation and sale of blood by intravenous drug users. American joumal of public health 1991; 8, 5: 631-633.

(27) Caplan A L. Blood, sweat, tears, and profits: the ethics of the sale and use of patient derived materials in biomedicine. Paper prepared for the American Medical Clinical Research (AMCR) Public Policy Symposium, 42nd Annual Meeting, Washington, DC, 1985 May 6.

(28) For more on screening and registering donors, see Pindych J. AIDS and the blood service system. In: Griggs J, ed. AIDS: public policy dimensions. New York: United Hospital Fund of New York, 1987: 85-100; and Eckert R D. Blood, money and monopoly. See reference (15): 15 .

(29) Kessel R A. Transfused blood, serum hepatitis, and the Coase theorem. Fournal of law and economics 1984; 17: 287-288. See also Sapolsky H M. Is honesty the best policy?: reference (28) AIDS: Public Policy Dimensions: 112.

(30) See reference (29): Kessel: 286.

(31) For desperation in organ markets, see Gorovitz S. Testimony [on buying, selling and brokering human organs]. In: Humber J J, Almeder R F. Biomedical ethics reviews Clifton N J: Humana Press, 1985: 5-12.

(32) See reference (7): Hagen: 35-36.

(33) See Peces-Barba G. Humanismo y solidaridad como valores de una sociedad avanzada [Humanism and solidarity as values of a developed society]. In: Garcia de Lorenzo R, Cabra de Luna M A, Giménez-Reyna Rodriguez E, eds. Las entidades no lucrativas de caracter social y humanitario. [Social and humanitarian not-forprofit values]. Madrid: Col 'Solidaridad' 1, La Ley, 1991: 13-62. 